\title{
The Fabrications and Optical Properties of AICrNO Based Solar Selective Absorber Coatings by Cathodic Arc Ion Plating
}

\author{
Yingjie XU, Dianqing GONG, Rui NIU, Zeqin CUI \\ College of Materials Science and Engineering \\ Taiyuan University of Technology \\ Taiyuan, China \\ e-mail: Xuyingjie183@163.com, gongdianqing@tyut.edu.cn,623067977@qq.com, cuizeqin@tyut.edu.cn
}

\begin{abstract}
A series of AlCrNO based solar selective absorber coatings were deposited by cathodic arc ion plating on three kinds of different infrared reflectors $(\mathrm{AlCr}, \mathrm{Cu}, \mathrm{Cr})$ and with different deposition currents respectively. The surface morphology, phase structure and surface roughness were characterized by field emission scanning electron microscopy (FE-SEM), X-ray diffraction (XRD), and roughmeter respectively. The results show that the AlCr-AlCrNO based coating exhibited a high absorptance of 0.91 and an emittance of 0.52 when $\mathrm{AlCr}$ was served as infrared reflector. Meanwhile, a higher absorptance $(\alpha=0.92)$ of $\mathrm{AlCr}-\mathrm{AlCrNO}$ based coating was obtained when varying deposition current from 50 A to 60 A. Moreover, the roughness is one of impacts on the emittance. Increasing the deposition current to 70 A brings about the raising of the roughness, increasing the emittance therefore.
\end{abstract}

Keywords-solar selective absorber coating; optical properties; infrared reflectors; cathodic arc ion plating

\section{INTRODUCTION}

Nowadays, our society is facing more and more serious environment pollution and energy shortage. To solve these problems, researchers have paid great attention to solar energy because of its huge reserve and cleanness. One of the alternative ways to collect solar energy is to convert it into thermal energy and then further convert the thermal energy to electric energy, which is usually called as concentrating solar power system (CSP). Solar selective absorbing coatings, as the core part among the system, play a significant role in CSP [1]. To achieve as high conversion efficiency as possible, the main requirements for the solar selective absorbing coatings are high absorptance $(\alpha)$ in the solar radiation wavelength range $(0.3-2.5 \mu \mathrm{m})$ and low thermal emittance $(\varepsilon)$ in the infrared wavelength region $(2.5-25 \mu \mathrm{m})$ [2].

As one of the cermet coatings, AlCr based multi-layer solar selective absorbing coating is widely used to obtain high spectral selective property [3-7]. H.D. Liu et al. have optimized AlCrO-based absorber with a absorptance of 0.942 and emittance of 0.094 for solar selective applications [8]. However, there are not so many researches about the impact of different infrared reflectors and different deposition currents on its optical properties. In this work, we fabricated a series of $\mathrm{AlCrNO}$ based solar selective absorber coatings on $\mathrm{AlCr}, \mathrm{Cu}, \mathrm{Cr}$ infrared reflectors respectively. Further, the deposition currents were changed to acquire the relationship between the optical properties and deposition currents. 316L stainless steel (S-S) was chosen as substrate.

\section{EXPERIMENT}

Fig.1. Shows the schematic diagram of the AlCrNO based solar selective absorber coating, which is deposited on the $\mathrm{S}-\mathrm{S}$ substrates $(30 \times 40 \mathrm{~mm})$. The multi-layer tandem absorber, from the bottom to the top, consists of an infrared reflector, two absorbers with different metal volume fractions by adjusting the ratio of $\mathrm{O}_{2} / \mathrm{N}_{2}$, the $\mathrm{N}_{2}$ flow rate was $40 \mathrm{sccm}$ for the $\mathrm{AlCrN} ; \mathrm{N}_{2}(20 \mathrm{sccm})$ and $\mathrm{O}_{2}(20 \mathrm{sccm})$ for the AlCrON. In order to further decrease the reflectance, an antireflection layer of $\mathrm{AlCrO}$ is deposited on the top of the coating and the $\mathrm{O}_{2}$ flow rate was $40 \mathrm{sccm}$.

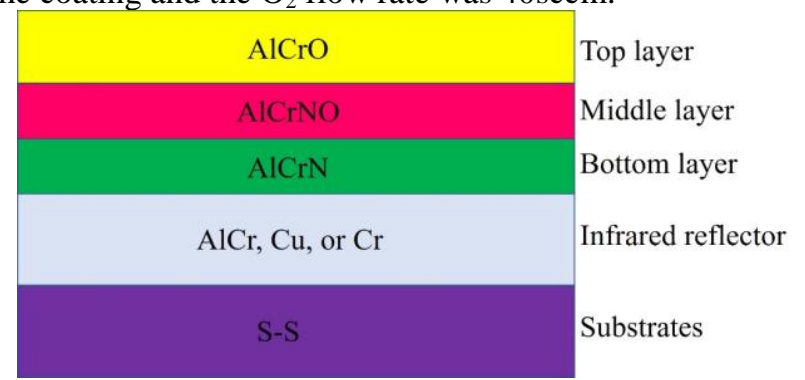

Figure 1. Schematic diagram of AlCrNO based solar selective absorber coating deposited on S-S substrate.

TABLE I. THE DEPOSITION PARAMETERS OF THREE DIFFERENT KINDS OF INFRARED REFLECTORS

\begin{tabular}{llll}
\hline & $\mathrm{AlCr}$ & $\mathrm{Cu}$ & $\mathrm{Cr}$ \\
\hline $\begin{array}{l}\text { Substrate temperature } \\
\left({ }^{\circ} \mathrm{C}\right)\end{array}$ & 250 & 250 & 250 \\
Bias voltages $(\mathrm{V})$ & -150 & -150 & -150 \\
Working pressure (Pa) & 0.9 & 0.9 & 0.9 \\
Deposition currents (A) & 50 & 60 & 80 \\
Deposition time (s) & 240 & 240 & 240 \\
\hline
\end{tabular}

The multi-layer AlCrNO based solar selective absorber coatings were prepared by a cathodic arc ion plating system, which was equipped with a $\mathrm{Al}_{70} \mathrm{Cr}_{30}$ target $(99.9 \%)$ on the side walls of the chamber. Firstly, the designed AlCrNO based coatings with three different kinds of infrared reflectors ( $\mathrm{AlCr}, \mathrm{Cu}$ and $\mathrm{Cr}$ ) were deposited onto stainless steel substrates respectively. The preparation parameters were listed in Table 1 and Table 2. Afterwards, $\mathrm{AlCrN} / \mathrm{AlCrON} / \mathrm{AlCrO}$ coatings were deposited on $\mathrm{AlCr}$ infrared reflector with the deposition currents variation from $50 \mathrm{~A}$ to $70 \mathrm{~A}$, named $\mathrm{A} 1, \mathrm{~A} 2$ and $\mathrm{A} 3$ respectively, the 
detailed parameters of $\mathrm{AlCr}$ infrared reflector were listed in Table 3 and the AlCrN/AlCrON/AlCrO coatings were prepared according to the parameters of Table 2.

TABLE II. THE DEPOSITION PARAMETERS OF EVERY SINGLE LAYER OF AlCrNO BASED COATINGS

\begin{tabular}{llll}
\hline & \multicolumn{1}{c}{$\mathrm{AlCr}$} & $\mathrm{AlCrON}$ & $\mathrm{AlCrO}$ \\
& $\mathrm{N}$ & & \\
\hline Deposition currents (A) & 50 & 50 & 50 \\
Bias voltages (V) & 150 & 150 & 150 \\
$\mathrm{~N}_{2}(\mathrm{sccm})$ & 40 & 20 & 0 \\
$\mathrm{O}_{2}(\mathrm{sccm})$ & 0 & 20 & 40 \\
$\mathrm{Ar}(\mathrm{sccm})$ & 50 & 50 & 50 \\
Working pressure (Pa) & 0.8 & 0.8 & 0.8 \\
Deposition time (s) & 180 & 180 & 180 \\
Substrate temperature & 250 & 250 & 250 \\
$\left({ }^{\circ} \mathrm{C}\right)$ & & & \\
\hline
\end{tabular}

TABLE III. THE PREPARATION PARAMETERS OF AlCrN/AlCrON/AlCrO COATINGS WITH THREE DIFFERENT KINDS OF DEPOSITION CURRENTS

\begin{tabular}{llll}
\hline & A1 & A2 & A3 \\
\hline Deposition currents (A) & 50 & 60 & 70 \\
Bias voltages (V) & 150 & 150 & 150 \\
Ar flow (sccm) & 50 & 50 & 50 \\
Working pressure (Pa) & 0.8 & 0.8 & 0.8 \\
Deposition time (s) & 180 & 180 & 180 \\
Substrate temperature & 250 & 250 & 250 \\
$\left({ }^{\circ} \mathrm{C}\right)$ & & & \\
\hline
\end{tabular}

After deposition, the structures of the coatings were characterized by X-ray diffraction (XRD) using $\mathrm{Cu} \mathrm{K \alpha}$ radiation. The morphologies of the multilayered coatings were investigated by FE-SEM equipped with an energy disperse spectroscopy (EDS). The surface roughness of the samples was measured by a roughness tester. The normal reflectance was measured for the wavelength region of 0.3-2.5 $\mu \mathrm{m}$ by Ultraviolet/visible/near-infrared spectrophotometer, and A Fourier-transform infrared spectrophotometer for the region of 2.5-25 $\mu \mathrm{m}$. The calculation of absorptance and emittance were shown in equation (1), (2) respectively.

$$
\begin{gathered}
\alpha=\frac{\int_{0.3}^{2.5}(1-R(\lambda)) \cdot I_{s o l} \cdot d \lambda}{\int_{0.3}^{2.5} I_{s o l} \cdot d \lambda} \\
\varepsilon=\frac{\int_{2.5}^{25}(1-R(\lambda)) \cdot I_{b \lambda} \cdot d \lambda}{\int_{2.5}^{25} I_{b \lambda} \cdot d \lambda}
\end{gathered}
$$

where $I_{s o l}$ and $I_{b \lambda}$ are solar spectrum irradiance and the blackbody radiation, $R(\lambda)$ is the spectrum reflectance.

\section{RESULT AND DISCUSSION}

Fig. 2 were the optical properties of the coatings with different infrared reflectors. As shown in Fig.2, the absorptance of these three coatings were $0.90,0.89,0.91$ respectively.

There exist scarcely changes on absorptance of these coatings, which suggested the different infrared reflectors impact little on the absorptance when the two absorbers and an antireflection layer were same. However, the emittance of these coating varied along with the differences of infrared reflectors. The $\mathrm{AlCr}$ exhibited the best infrared reflection as an infrared reflector in this experiment while the coatings with $\mathrm{Cu}$ and $\mathrm{Cr}$ infrared reflectors exhibited a relatively poor infrared reflection. That demonstrates that $\mathrm{AlCr}$ is a better candidate to act as an infrared reflection.
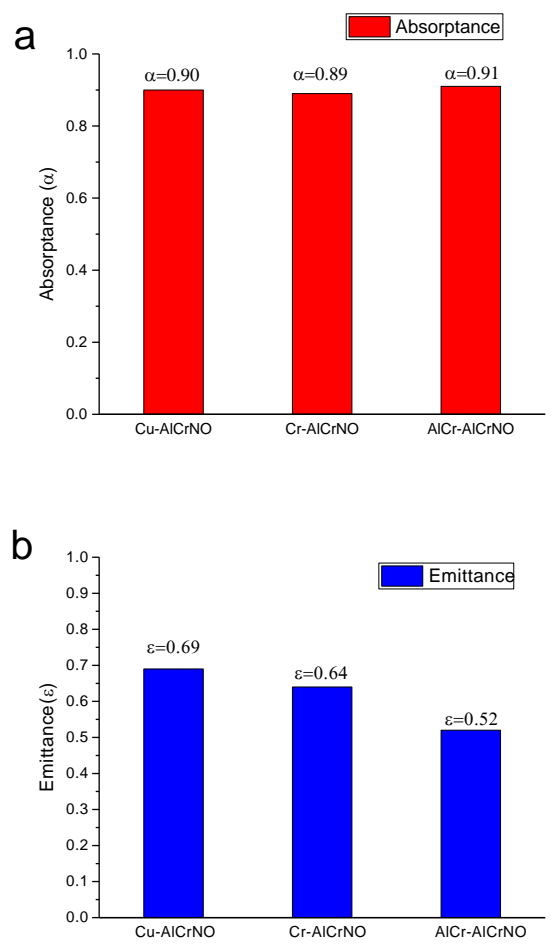

Figure 2. The absorptance (a) and the emittance (b) of AlCrNO based solar selective absorber coatings with three infrared reflectors respectively.

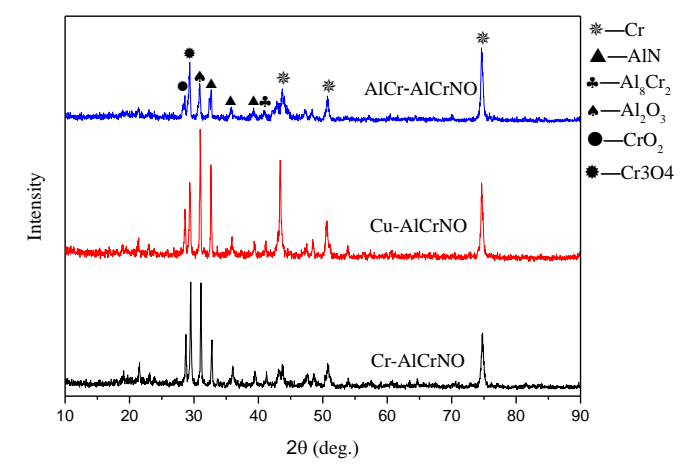

Figure 3. The XRD patterns of the AlCrNO based coatings deposited on three infrared reflectors $(\mathrm{AlCr}, \mathrm{Cu}, \mathrm{Cr}$ ) respectively.

Fig.3. shows the XRD patterns of the AlCrNO based coatings deposited on $\mathrm{AlCr}, \mathrm{Cu}, \mathrm{Cr}$ infrared reflectors respectively. The phase structure of the samples was mainly composed of $\mathrm{Cr}$, AlN, $\mathrm{Al}_{2} \mathrm{O}_{3}, \mathrm{Cr}_{3} \mathrm{O}_{4}, \mathrm{Al}_{8} \mathrm{Cr}_{2}$ and $\mathrm{CrO}_{2}$. The strongest peak from the $\mathrm{Cr}$ (220) plane was observed from the $\mathrm{AlCr}-\mathrm{AlCrNO}$ and $\mathrm{Cr}-\mathrm{AlCrNO}$ coating while the $\mathrm{Cr}$ 
(111) plane was observed from $\mathrm{Cu}$ - AlCrNO. Due to $\mathrm{Cr}$, and $\mathrm{Al}_{8} \mathrm{Cr}_{2}$ in the bottom and middle layer, which belong to metal composition, and AlN, in the absorbing layers which belongs to ceramic, the coating was regarded as a tandem metallic ceramic one. In these absorbing layers, when solar light radiates the metallic ceramic layer, the role of the metallic particles in the ceramic is to promote the solar absorptance by reason of their high intrinsic absorption [9]. Further, aluminum oxide $\left(\mathrm{Al}_{2} \mathrm{O}_{3}\right)$ and chromium oxide $\left(\mathrm{Cr}_{3} \mathrm{O}_{4}\right.$ and $\left.\mathrm{CrO}_{2}\right)$ on the surface contributed to anti-reflection of coatings [10].

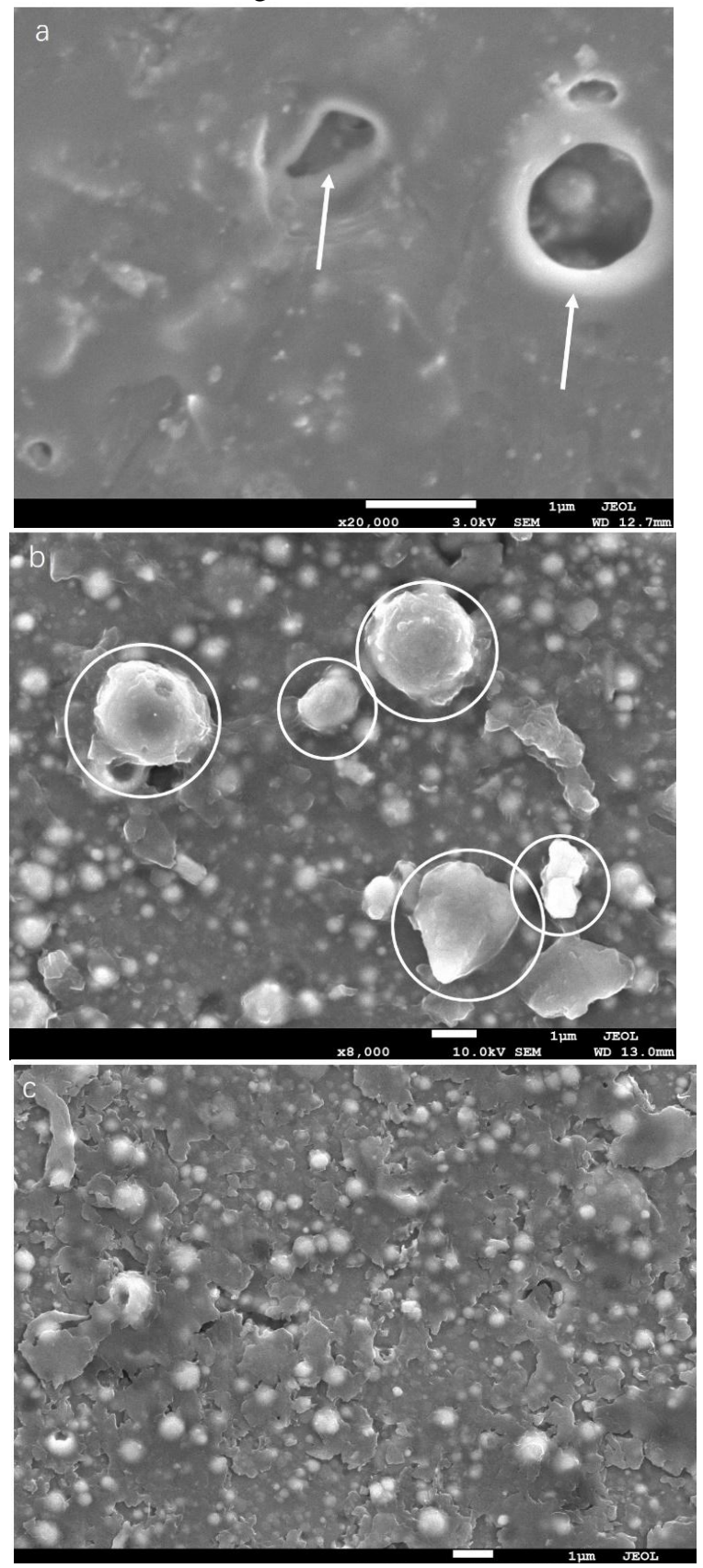

Figure 4. The microstructure images of $\mathrm{AlCrNO}$ based coating with $\mathrm{Cr}$ infrared reflector (a); $\mathrm{Cu}$ infrared reflector (b); and $\mathrm{AlCr}$ infrared reflector (C).
Fig.4 shows the microstructure images by FE-SEM of AlCrNO based coatings of three kinds of infrared reflectors. In Fig. 4a, two obvious holes (at the arrowheads) were observed on the surface, the sizes of which were $0.8 \mu \mathrm{m}$ and $1.5 \mu \mathrm{m}$ respectively. The sizes were within the range of $0.3-2.5 \mu \mathrm{m}$. Therefore, there were reasons to believe the formation of optical trap, which would enhance the optical reflection in the holes rather than back to the atmosphere. As a result, the optical absorptance was further improved. In Fig. 4b, as encircled by white ring, the big particles $(\geq 2 \mu \mathrm{m})$ were observed on the surface, which was due to splash during deposition. Nevertheless, in Fig.4c, the surface was full of small particle $(\leq 1 \mu \mathrm{m})$. The hole and particle sizes impacted the thermal emittance of the coating generally. The big particle increased the thermal radiation area, thus leading to a high emittance. Further, the roughness ( $\mathrm{Ra}$ ) of these coatings was measured to explain the macromorphology and the results were listed in Table 4. The roughness of $\mathrm{Cu}-\mathrm{AlCrNO}$ was $0.25 \mu \mathrm{m}$, much bigger than the rest two coatings. So, as discussed above, the AlCrNO based coating with $\mathrm{AlCr}$ infrared reflector exhibited the lowest emittance compared with the other two coatings.

TABLE IV. THE ROUGHNESS OF THE Cr- AlCrNO, Cu- AlCrNO AND $\mathrm{AlCr}-\mathrm{AlCrNO}$

\begin{tabular}{lc}
\hline & Roughness (Ra) \\
\hline $\mathrm{Cr}-\mathrm{AlCrNO}$ & $0.13 \mu \mathrm{m}$ \\
$\mathrm{Cu}-\mathrm{AlCrNO}$ & $0.25 \mu \mathrm{m}$ \\
$\mathrm{AlCr}-\mathrm{AlCrNO}$ & $0.12 \mu \mathrm{m}$ \\
\hline
\end{tabular}

Moreover, EDS tests were carried out to figure out the compositions of the surface in Fig. 5. As displayed in Fig. $5 \mathrm{a}$, the flat surface composition (atomic percent) consisted of $\mathrm{Al}(48.4 \%), \mathrm{Cr}(28.3 \%)$ and $\mathrm{O}(23.3 \%)$ for $\mathrm{Cr}-\mathrm{AlCrNO}$ coating. In Fig. $5 \mathrm{~b}$ and c, the particles consisted of $\mathrm{Al}(19.5 \%$ and $25.4 \%), \mathrm{Cr}(18 \%$ and $25.3 \%)$ and $\mathrm{O}(55.3 \%$ and $45.9 \%)$ for $\mathrm{Cu}-\mathrm{AlCrNO}$ and $\mathrm{AlCr}-\mathrm{AlCrNO}$ coating respectively. In Fig. 5, the content of $\mathrm{O}$ in $\mathrm{Cu}-\mathrm{AlCrNO}$ and $\mathrm{AlCr}-\mathrm{AlCrNO}$ was much higher than in $\mathrm{Cr}-\mathrm{AlCrNO}$. That difference meant more metallic oxide in the $\mathrm{Cu}-\mathrm{AlCrNO}$ and $\mathrm{AlCr}-\mathrm{AlCrNO}$ coatings, exhibiting a high antireflection.

Fig.6 were the reflectance curves of these coatings, which were measured by a Shimadzu UV3600 UV/VIS/IR spectrophotometer and Bruker Tensor 27 Fourier Transform spectrometer. In the wavelength of $0.3-2.5 \mu \mathrm{m}$, minimum points of reflectance were found in the curves. The $\mathrm{X}$-coordinates were $0.38 \mu \mathrm{m}, 0.75 \mu \mathrm{m}$ and $1.2 \mu \mathrm{m}$ for the blue curve; $0.40 \mu \mathrm{m}, 0.53 \mu \mathrm{m}$ and $0.88 \mu \mathrm{m}$ for the red one; $0.44 \mu \mathrm{m}$, $0.71 \mu \mathrm{m}$ and $2.3 \mu \mathrm{m}$ for the black curve respectively. According to optical theories, the minimum point of reflectance was caused by optical destructive interference when the optical thickness equals to the odd times of quarter wavelength. That illustrated the formation of optical destructive interference in these multi-layer solar selective coatings. Hence, a proper solar selective coating with a high absorptance was obtained. Nevertheless, a low reflectance was observed in the range of 2.5-8 $\mu \mathrm{m}$, which meant a poor infrared reflection of these coatings. Still, the reflectance spectra of the three showed that there were red-shifts toward 
long wavelength occurred in the range of $2.5-25 \mu \mathrm{m}$ to different degrees. It is well recognized that in the infrared wavelength, red-shift will cause the increasing of emittance. The surface big droplets and holes might be the reason for the red-shift.
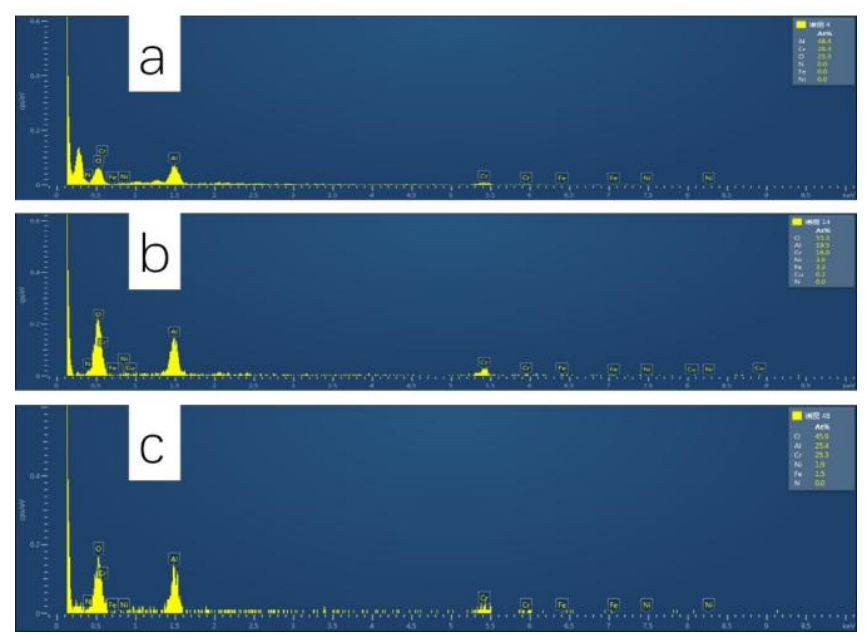

Figure 5. EDS tests on the surface of AlCrNO based coating with $\mathrm{Cr}$ infrared reflector (a); $\mathrm{Cu}$ infrared reflector (b); and $\mathrm{AlCr}$ infrared reflector (C).

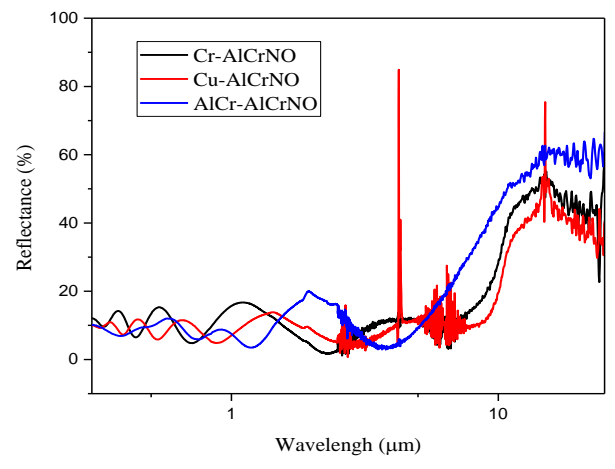

Figure 6. The reflectance curves of AlCrNO based coatings with $\mathrm{Cr}, \mathrm{Cu}$, $\mathrm{AlCr}$ infrared reflectors respectively.

However, compared with the other two spectra, the red-shift of the blue curve was more slightly and it showed a higher absorbance, a series of $\mathrm{AlCrNO}$ based coatings were also prepared on the same $\mathrm{AlCr}$ infrared reflector figure out an optimized coating by varying the deposition current from $50 \mathrm{~A}$ to $70 \mathrm{~A}$, the parameters of which were listed in Table 5. The results of the coatings were listed in Table 5. Seen from Table 5, the absorptance kept nearly unchanged. Nonetheless, the emittance increased along with the rising of deposition current. Generally, on the one hand, rising the current means increasing the content of metal vapored from the target, thus raising the content of metallic composition and further increasing the absorptance. On the other hand, with the rising of current during deposition, there will be bigger droplet on the surface, thus increasing the thermal radiation area of the surface. Consequently, the emittance of the coatings increased on condition that the current was risen. Table 6 lists the roughness of the coatings with different deposition current.

TABLE V. THE OPTICAL PROPERTIES OF THE COATINGS WITH DIFFERENT DEPOSITION CURRENT

\begin{tabular}{ccc}
\hline & Absorptance & Emittance \\
\hline A1 & 0.91 & 0.52 \\
A2 & 0.92 & 0.58 \\
A3 & 0.91 & 0.64 \\
\hline
\end{tabular}

TABLE VI. THE ROUGHNESS OF THE COATINGS WITH DIFFERENT DEPOSITION CURRENT

\begin{tabular}{cccc}
\hline & $50 \mathrm{~A}$ & $60 \mathrm{~A}$ & $70 \mathrm{~A}$ \\
\hline Roughness $(\mu \mathrm{m})$ & 0.131 & 0.146 & 0.160 \\
\hline
\end{tabular}

\section{CONCLUSION}

In summary, a series of AlCrNO based solar selective absorbing coating are deposited with three kinds of infrared reflectors ( $\mathrm{AlCr}, \mathrm{Cr}$ and $\mathrm{Cu}$ ). And the $\mathrm{AlCr}-\mathrm{AlCrNO}$ coating exhibits a better absorptance of 0.91 and an emittance of 0.52 . The surface morphology impacts the emittance. Big droplets in the surface increase the thermal radiation area, leading to the rising of the emittance. Meanwhile, deposition current also impacts optical properties, a bigger current increases the content of metallic composition, which leads to the increasing of the absorptance.

Further study on the relationship between the deposition current and the optical constant (refractive index and extinction coefficient) will be carried on.

\section{ACKNOWLEDGMENT}

This work is supported by the National Natural Science Foundation of China (Grant No. 51402208) and State Key Laboratory of Advanced Technology for Materials Synthesis and Processing (Wuhan University of Technology) (Grant No. 2016-KF-11).

\section{REFERENCES}

[1] Selvakumar N, Barshilia HC. Review of physical vapor deposited (PVD) spectrally selective coatings for mid- and high-temperature solar thermal applications. Solar Energy Materials and Solar Cells. 2012;98:1-23.

[2] Gong D, Liu H, Luo G, Zhang P, Cheng X, Yang B, et al. Thermal aging test of AlCrNO-based solar selective absorbing coatings prepared by cathodic arc plating. Solar Energy Materials and Solar Cells. 2015;136:167-71.

[3] Kotilainen M, Honkanen M, Mizohata K, Vuoristo P. Influence of temperature-induced copper diffusion on degradation of selective chromium oxy-nitride solar absorber coatings. Solar Energy Materials and Solar Cells. 2016;145:323-32.

[4] Tsai TK, Li YH, Fang JS. Spectral properties and thermal stability of CrN/CrON/Al 2 O 3 spectrally selective coating. Thin Solid Films. 2016;615:91-6.

[5] Wang C, Shi J, Geng Z, Ling X. Polychromic Al-AlN cermet solar absorber coating with high absorption efficiency and excellent durability. Solar Energy Materials and Solar Cells. 2016;144:14-22.

[6] Zou C, Huang L, Wang J, Xue S. Effects of antireflection layers on the optical and thermal stability properties of a spectrally selective CrAlN-CrAlON based tandem absorber. Solar Energy Materials and 
Solar Cells. 2015;137:243-52.

[7] Zou C, Xie W, Shao L. Functional multi-layer solar spectral selective absorbing coatings of AlCrSiN/AlCrSiON/AlCrO for high temperature applications. Solar Energy Materials and Solar Cells. 2016;153:9-17.

[8] Liu HD, Wan Q, Li X, luo C, Theiss W, Zhang LH, et al. Optimization of AlCrO-based absorber with Mo infrared reflector for solar selective applications. Vacuum. 2016;128:27-33.
[9] Rebouta L, Sousa A, Capela P, Andritschky M, Santilli P, Matilainen A, et al. Solar selective absorbers based on Al2O3:W cermets and AlSiN/AlSiON layers. Solar Energy Materials and Solar Cells. 2015; 137:93-100.

[10] Liu HD, Wan Q, Xu YR, luo C, Chen YM, Fu DJ, et al. Long-term thermal stability of CrAlO-based solar selective absorbing coating in elevated temperature air. Solar Energy Materials and Solar Cells. 2015;134:261-7. 